\title{
El Mercadeo en las Microempresas
}

\author{
Clemenza de Araujo, Caterina * \\ Ruben Araujo **
}

\section{Resumen}

El objetivo central de este artículo es determinar las actividades de mercadeo que llevan a cabo los microempresarios, en la comercialización de sus productos y/o servicios. El tipo de investigación es descriptiva. Se seleccionó como objeto de estudio a un segmento del sector microempresarial que desarrolla actividades económicas en el área de la producción y en la prestación de servicios, localizados en la ciudad de Maracaibo del Estado Zulia, tomándose 52 microempresarios que fueron asistidos financiera $y$ técnicamente por la Fundación de Apoyo a la Economía Popular durante el segundo semestre de 1995, lo cual justificó que se hiciese un Censo. Como instrumento de recolección de datos, se aplicó una encuesta tipo entrevista semi-estructurada. Los resultados obtenidos muestran que el mercadeo es débil en las microempresas estudiadas. Los microempresarios excepcionalmente investigan su mercado y planean sus estrategias de mercadeo, se limitan a vender lo que producen $\sin$ una acción de mercadeo definida.

Palabras Claves:Mercadeo, comercialización, microempresa, economía popular, economía informal.

Recibido: $20-07-96$ Aceptado:19-12-96

- Economista, Magister en Gerencia de Empresas. Menciŏn Mercadeo. Investigadora - Profesora Agregado a Dedicación Exclusiva. Universidad del Zulia. Facultad de Ciencias Económicas y Sociales. Instituto de Investigación. Departamento de Estudios Regionales y Urbanos. Maracaibo - Estado Zulia - Venezuela. Teléfonos Fax:00 - 58 - 61 596513, 00 - 58 - 61 975738, Hab: 00 - 58

- 61533156 E-Mail cclemenz europa.ica.luz.ve. Favor enviar correspondencia a la siguiente dirección: Res. La Puerta de Ciudadela Faría. Edif. La Mesa. Apto. 5-3. Maracaibo- Edo. Zulia.

** Magister en Gerencia de Empresas 


\section{Marketing in small Business}

\section{Abstract}

The Present research has as an objetive : to determine the marketing activities carried on by micro-enterprises people in the trading of their products and/or services. It is a descriptive research which considers as population subject of study a segment of the micro-enterprise sector which develops economical activities in the production an the services areas located in Maracaibo (Zulia State). Taking a population of 52 micro-enterprises people who were assisted by the Foundation of Support to the Popular Economy during the second semester of 1995, which justifies the Census that was made. As an instrument of data collecting, it was applied a survey in a type of semi-structured interview. The results obtained showed that marketing in the studied micro-enterprises is weak; these people very exceptionally research their market and plan their marketing strategies. They are limited to sell what they produce without taking a defined marketing action.

Key words: Marketing, micro-enterprise, trading.

\section{Introducción}

El presente artículo ha sido motivada por el poco énfasis, que dentro de los Programas de Apoyo a las Microempresas, se le ha brindado al área de mercadeo. Los lineamientos de estos programas, han estado enmarcados en la operacionalización de políticas de financiamiento y en cierta medida en la puesta en práctica de módulos de capacitación sobre formación administrativa, dejando rezagados otros aspectos concernientes a la comercialización, la cual es un elemento sumamente importante, que si no se le brinda la debida atención atenta contra el éxito de los programas de apoyo a las microempresas. Estos programas deben formularse con una visión holística de la microempresa, de modo que los objetivos que alli se plantean y las acciones a seguir para lograr esos objetivos, capaci- ten a los empresarios informales de manera integral, en aspectos de organización y dirección, comercialización y financiamiento; conduciendo así a que la microempresa se desarrolle, fortalezca y se consolide.

Con este artículo se pretende contribuir, en cierta medida, a que los organismos involucrados en mejorar las condiciones del sector microempresarial, tengan un norte o punto de partida, para formular las estrategias que deben seguir en el área de mercadeo, con el fin de apoyar a este importante sector de la economía.

\section{Consideraciones Generales}

En América Latina; el Sector Informal Urbano, se ha desarrollado en las últimas décadas, como un fenómeno social de gran significación, debido a la 
grave crisis económica y social que han venido enfrentando estos países del Continente.

Tomando en consideración la creciente presencia del sector informal urbano en la vida económica de los países de América Latina, éstos han dirigido su atención a formular e implementar políticas de apoyo a este sector económico, con la finalidad de incorporarlos a los planes formulados por las políticas gubernamentales destinadas a enfrentar los altos costos sociales que ha producido la crisis.

"El marco conceptual en el que se desenvuelven estas políticas contempla ideas innovadoras donde se destaca que los pobres son capaces de producir ahorro y generar ingresos suficientes para aliviar de forma significativa su condición económica y de vida en general. Asimismo, se plantea que las micro y pequeñas empresas pueden generar empleo, ya que requieren niveles de inversión más bajos que otros sectores, además de ser intensivas en la utilización de mano de obra" (Romero, 1994: 14).

En la década de los ochenta, el Estado Venezolano se interesa por formular programas de apoyo al sector informal y en especial a las unidades de producción a pequeña escala, iniciándose estos programas en el Estado Lara. Pero es, a partir de 1989 cuando, a través de la Comisión Presidencial para el Enfrentamiento de la Pobreza, decide incluir el Programa de Apoyo a la Economía Popular como parte de sus políticas sociales.
Anterior a esto, las microempresas eran asistidas por organismos no gubernamentales; tal es el caso de: La Fundación Mendoza, Centro al Servicio de la Acción Popular (CESAP), Central Cooperativa Nacional de Venezuela (CECONAVE), entre otros, contando algunos de ellos, con recursos asignados por organismos financieros internacionales como el Banco Mundial y el Banco interamericano de Desarrollo.

Es importante resaltar, que los programas de apoyo a la economía popular, básicamente están orientados a brindar asistencia financiera, dejando en segundo término, otros aspectos sumamente importantes para el desarrollo de estas pequeñas unidades de producción, como por ejemplo, la comercialización.

Hasta el momento el tema de comercialización en las microempresas, ha sido muy poco desarrollado y estudiado por instituciones y entidades que se ocupan a nivel Nacional e Internacional de implementar los programas de apoyo a los microempresarios. El esfuerzo ha estado fundamentalmente en función de la operacionalización de políticas de financiamiento y en cierta medida en la puesta en práctica de módulos de capacitación sobre formación administrativa.

El poco desarrollo programático que ha tenido todo lo referente a la comercialización es un elemento que atenta contra el éxito de los programas de apoyo de la microempresa, tomando en consideración que es uno de los factores básicos que determinan en parte el comportamiento económico de estas organizaciones.

En el año 1992, se realizó en la 
ciudad de Caracas un Seminario Internacional de Microempresas, en donde se aborda con mayor profundidad el tema de la Comercialización. En este Seminario, se evaluaron las experiencias organizativas de comercialización de insumos y productos de las microempresas.

Los esfuerzos realizados en paises como Colombia, Costa Rica y Perú estan orientados a la creación de programas de mercadeo con y para el sector microempresarial. Los programas desarrollados generan un sistema concentrado de atención institucional en concordancia con las necesidades locales y regionales de la microempresa. Específicamente, en Colombia, el último documento publicado por el Consejo Nacional de Política Económica y Social (CONPES), establece la comercialización y la tecnología como elementos vitales del desarrollo del sector microempresarial. A partir de este momento se crea formalmente el "Programa de Mercadeo de Apoyo a la Microempresa" el cual parte de la base que para poder vender más y tener acceso a nuevos nichos de mercado, el sector microempresarial, debe alcanzar mayores niveles de productividad, competitividad y calidad. Conceptualmente, este programa se fundamenta en dos categorias especificas: Integridad e Inter - institucionalidad, las cuales son caracteristicas del programa de mercadeo que posibilita de manera eficiente y eficaz el logro del objetivo propuesto en el programa: Incrementar los ingresos del sector microempresarial (Quintero, 1992: 13).

En nuestro pais, existe un desarro- llo de formas solidarias de comercialización en el área de productos agrícolas y/o vinculadas con la alimentación (cooperativas), en donde se exponen y venden los productos a través de las ferias de consumo popular. Al mismo tiempo existen programas de apoyo sostenido de promoción por medio de las Expo - Ferias que desde algún tiempo se vienen realizando a través de la Fundación de Desarrollo de Microempresa del Estado Lara (FUNDEME) y la Fundación de Desarrollo y Apoyo a la Economía Popular (FUNDEPO) en el Estado Zulia. Por otra parte, se están llevando a cabo acciones progresivas y crecientes de apoyo a los microempresarios de la confección a través de la Asociación para el Trabajo Alternativo (ASOTRAL), donde se promueve $\theta$ integra a los microempresarios en el área.

Los anteriores programas, aún cuando son muy incipientes, persiguen elevar el porcentaje de participación de los productores en el margen de ganancias obtenidas al lograr mecanismos más directos de comercialización; lograr esfuerzos integradores para la adquisición de materia prima, maquinaria y repuestos en condiciones menos onerosas; acceder a mejores niveles de diseño y programación de la producción de acuerdo a la demanda, contratando colectivamente a expertos en mercadeo; realizar investigaciones de mercado permanentes; y poder contratar con el Estado, al tener en conjunto mayores cantidades de producto que ofrecer y mejores condiciones de calidad. 
Las actividades de mercadeo que desarrollan los microempresarios:

Cuando se desea abordar algún estudio relacionado con las actividades de mercadeo, se hace necesario referirse a las variables de mercadotecnia: a) factores que pueden ser controlados por la organización : producto, precio, promoción y distribución; y b) las relacionadas con el medio ambiente de la mercadotecnia, (donde los empresarios tienen poco o ningún control) (PRide y Ferrel, 1992: 18).

A continuación se analizan algunos aspectos contenidos en las entrevistas semi - estructuradas (realizadas a los

Figura 1

Distribución del producto o servicio en microempresas de Maracaibo

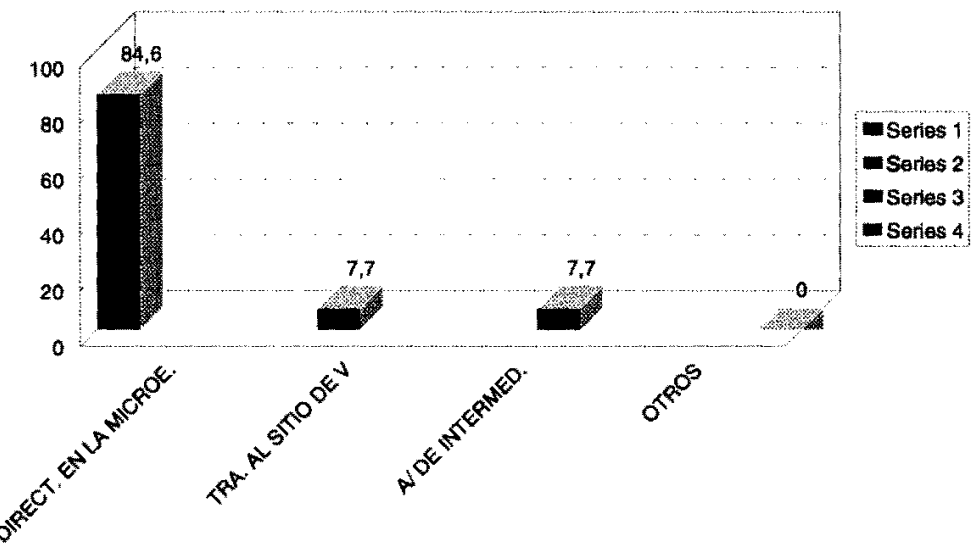

Figura 2

La comercialización de sus productos y/o servicios la realiza a nivel

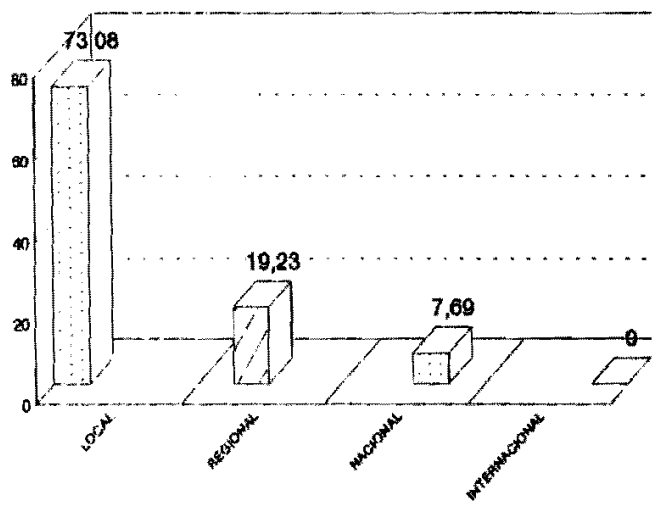


microempresarios seleccionados, ubicados en la ciudad de Maracaibo) tales como: precio, distribución y promoción de sus productos y/o servicios; factores externos que los afectan; análisis que ellos hacen de las condiciones de mercado; los criterios de segmentación del mercado que emplean, entre otros. Con el objetivo de determinar la naturaleza de las actividades de mercadeo que llevan a cabo para comercializar sus productos $y / o$ prestar sus servicios.

Al tratar de identificar las estrategias que utilizan los microempresarios para distribuir sus productos y/o prestar sus servicios, se evidenció que un alto porcentaje ( $85 \%$ ) distribuyen sus productos directamente en la microempresa, el resto utiliza la intermediación o los trasladan a otros puntos de venta. Por otro lado, más del $70 \%$ de la muestra comercializa sus productos o servicios a nivel local; el $19 \%$ comercializa a nivel nacional (Figuras 1 y 2).

La gran mayoría de los propietarios de los establecimientos informales encuestados, manifestaron que comercializaban directamente. Sin embargo, no hay que olvidar que existe un porcentaje que trabaja bajo pedido y que varios de sus clientes en realidad son intermediarios o empresas que subcontratan el trabajo informal, de modo que aún cuando el contacto del microempresario aparezca como directo con quienes le compran su producción o servicios, eso no significa que estos clientes sean los destinatarios finales. De modo que ese $85 \%$ que manifestó entregar su producción o servicios directamente a los consumidores puede estar sobreestimado por una confusión del microempresario y por el contrario, el porcentaje $(8 \%)$ que acude a la intermediación comercial probablemente sea mas alto. Sin embargo, se recomienda en una primera fase, el uso de intermediarios para colocar sus productos en el mercado, lo cual se explica en gran medida por su mayor eficiencia para poner los bienes a disposición de los mercados metas. Ya que éstos por medio de sus "contactos", su experiencia, especialización y escala de operaciones ofrece a los microempresarios más de lo que éstos puede lograr por sí mismos.

Es importante que el producto sea distribuido en los puntos de venta minoristas mas adecuados y de esta manera poderlo ofrecer a una gran mayoría de consumidores.

Es necesario puntualizar que las decisiones sobre el canal de comercialización se encuentran entre las más importantes que deben tomar los microempresarios, pues afectan de manera directa todas las demás decisiones de mercadotecnia. Sin embargo, debido al desconocimiento que tienen de la materia, prestan poca atención a sus canales de distribución, conduciendo al negocio con frecuencia a obtener resultados negativos.

Los microempresarios deben diseñar con mucha cautela sus canales de distribución, de manera tal, que puedan obtener ventajas comparativas y porqué no, hasta ventajas competitivas con respecto a otras empresas de su misma naturaleza.

Otro aspecto importante a considerar es la fijación de precios, ya que ésto se traduce en un problema de relevante importancia para los microempresarios; 
éstos comúnmente cometen errores como los siguientes: orientan excesivamente los precios hacia los costos; no revisan los precios con frecuencia, lo cual ocasiona que no reflejen realmente los cambios del mercado; fijan los precios sin tomar en consideración al resto de la mezcla de mercadotecnia y por último mantienen precios que no varían lo suficiente para diferentes productos y segmentos del mercado.

Las decisiones que los microempresarios deben tomar con respecto a la fijación de precios están influenciadas tanto por factores internos (objetivos de la empresa, los costos de producción y la estrategia de la mezcla de mercadotecnia), como por factores externos (la demanda, la competencia, las condiciones de la economía y las leyes o regulaciones públicas, entre otras). De tal manera, que fijar el precio de venta de los productos y servicios no es tarea fácil para los microempresarios, debido a que ellos deben tener un cierto grado de conocimien- to, que sólo se logrará en la medida que se capaciten gerencialmente (Figura No. 3).

En cuanto a la promoción que los microempresarios le hacen a sus productos y/o servicios se obtuvieron los siguientes resultados: el $62 \%$ de los microempresarios encuestados no los promocionan, lo cual indica una fuerte debilidad que puede ser subsanada implementando estrategias de promoción que conduzcan a que sus productos o servicios sean conocidos por los consumidores. Es conveniente señalar que los microempresarios argumentaron la imposibilidad de promocionar su negocio, debido a los altos costos en los cuales debían incurrir para tal fin.

Sólo el $38 \%$ de los entrevistados afirmaron promocionar sus productos 0 servicios a través de algún medio de comunicación. El $35 \%$ coloca avisos en sitios de compra, el $30 \%$ promociona a través de radio, el $20 \%$ lo hace en periódicos, revistas o catálogo, el resto lo hace

\section{Figura 3}

Criterios utilizados para fijar los precios en microempresas de Maracaibo

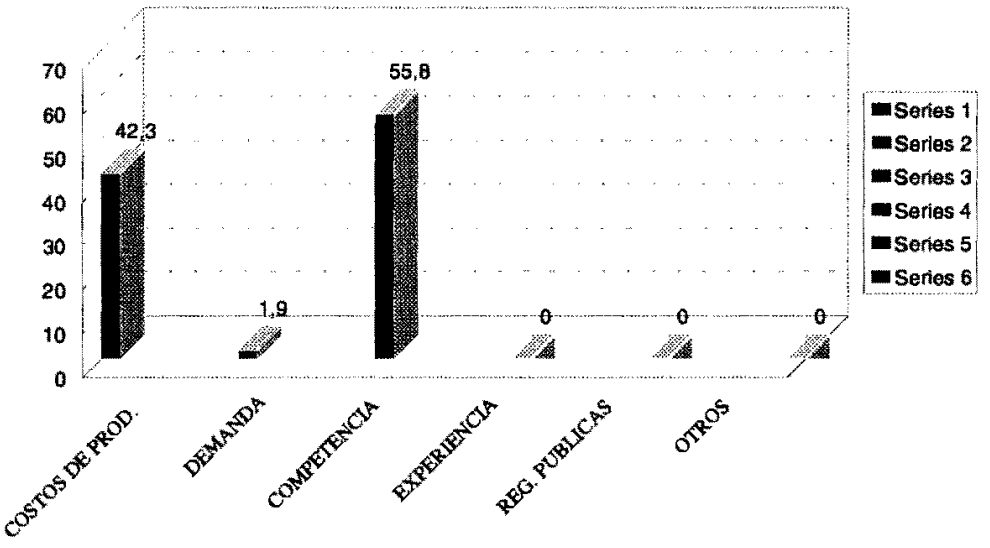


por medio de afiches y vallas publicitarias. Sin embargo el $60 \%$ afirma que la promoción la realiza ocasionalmente, el $35 \%$ lo hace semestralmente y el $5 \%$ una vez al mes.

Se debe señalar, que los microempresarios también se valen de exposiciones particulares, $o$ aquellas organizadas por organismos locales o regionales para dar a conocer los productos que ofrecen como pequeños productores; caso específico es la Fundación de Apoyo a la Economía Popular (FUNDEPO). Este organismo, a través de las llamadas Ferias de Exposición de la Economía Popular, permite que los microempresarios además de vender sus productos, sean conocidos por una buena parte de la población. Sin embargo pareciera que esta actividad no fuese suficiente ya que una parte considerable de microempresarios $(38 \%)$ manifestaron que existía desconocimiento de sus productos, lo cual guarda relación con la poca promoción que hacen de ellos.

Se aprecia además, que los $\mathrm{mi}$ croempresarios sujetos a estudio enfatizan sus esfuerzos en la promoción de ventas, para de esta manera, llamar la atención de los consumidores. Ofrecen incentivos que aportan un valor extra para los mismos, invitando y recompensando la rapidez de respuesta por parte de sus clientes. Esta herramienta de promoción de ventas, aún cuando crea una reacción más fuerte y rápida, dando espectacularidad $a$ las ofertas y acelerando las ventas deprimidas suele tener efectos a corto plazo y no resulta efectiva para crear una preferencia duradera por el producto.

En relación a la variable producto, se determinó la aceptación que los productos y/o servicios tienen en el mercado, de acuerdo a la opinión de los microempresarios entrevistados. Según ellos, los productos que elaboran o los servicios que prestan tienen una buena aceptación

Figura 4

Originalidad del diseño del producto o servicio en microempresas de

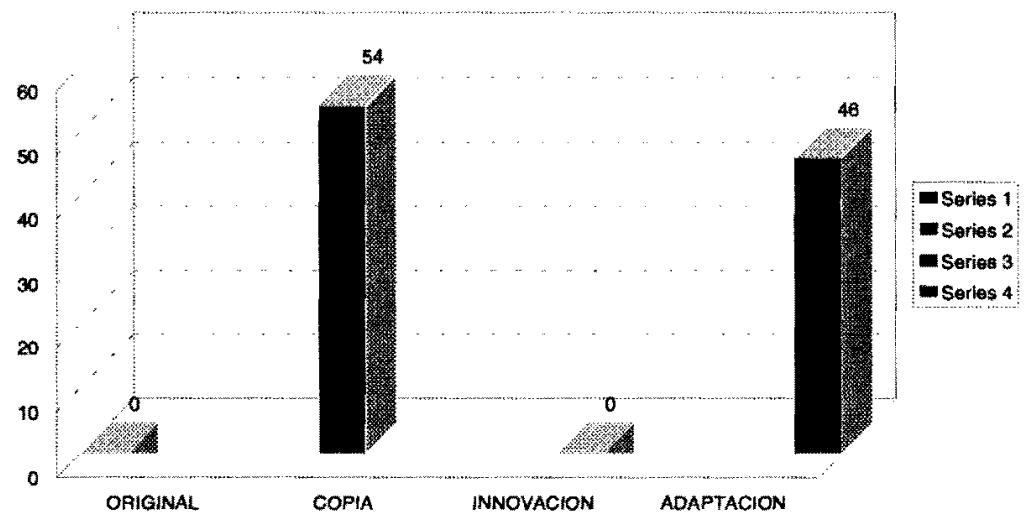


en el mercado, sólo el $\mathbf{2 8} \%$ afirmó que ésta era regular. Ninguno declaró tener poca aceptación.

Los microempresarios manifestaron que probablemente un segmento de su mercado meta aceptaba de manera regular sus productos, debido a que en ciertas ocasiones los artículos presentaban fallas en el diseño y terminado de los mismos.

En cuanto al "diseño", éstos afirmaron reproducir modelos pasados de moda y muy rara vez introducen innovaciones capaces de imponerse en el mercado. En las encuestas se muestra que el mayor número de microempresarios elaboran sus productos copiándose de otros modelos o adaptándolos a las necesidades de sus clientes. (Figura No. 4)

En referencia al "terminado" de sus productos, manifestaron, que en muchas ocasiones éste es defectuoso y da la impresión de mala calidad, debido a que ellos poseen maquinarias con frecuencia obsoletas, las cuales no son las más adecuadas para el fin que fueron adquiridas.

Estas dos debilidades (el diseño y el terminado) que presentan ciertas microempresas manufactureras, tienen graves repercusiones en el mercado.

Al analizar la manera de medir la aceptación de sus productos o servicios en el mercado, se pudo observar que el $50 \%$ de los microempresarios afirman que to hacen a través del comentario de los clientes; el $35 \%$ por el volumen de ventas y el resto por los reclamos y devoluciones.

Cuando se les preguntó a los microempresarios si sus productos y/o servicios tenían una marca definida, un porcentaje significativamente alto declaró que no la poseían, lo cual los coloca en una posición desfavorable respecto a la competencia (Figura No. 5).

Es importante puntualizar las ven. tajas que para los microempresarios tiene la acción de identificar sus productos o servicios con una marca que los diferencien de las demás microempresas. En la generalidad de los casos, las microempresas tienen un nombre que las identifica, pero usuaimente no se lo colocan al producto como una marca.

Figura 5

Utilización de marca definida del producto o servicio en

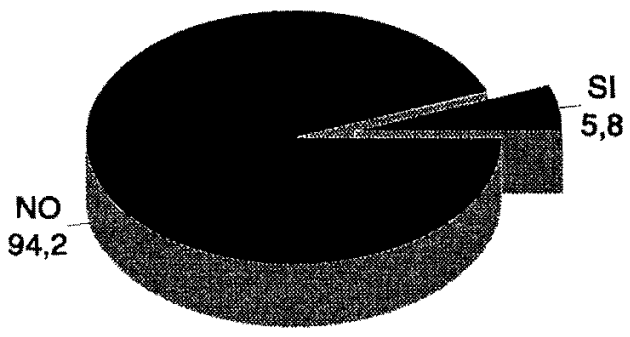


Los microempresarios deben tener presente que los consumidores ven la marca como una parte importante del producto y que las decisiones sobre la elección de una marca constituye un aspecto relevante de la estrategia de mercadeo del producto.

Colocarle una marca a sus productos puede resultar ventajoso debido a que identifica sus productos o servicios, facilita la compra repetitiva y los esfuerzos promocionales.

En relación a los factores externos, que los microempresarios consideran los afectan más, se tiene que uno de los principales cuellos de botella para el fortalecimiento y desarrollo de las microempresas lo constituyen las elevadas tasas de interés y el acceso al crédito. Este último, no siempre es oportuno y se les imponen unos requisitos que, además de excesivos, a menudo resultan complejos para los microempresarios. Dadas las dificultades de acceso al mercado formal de capital, la evidencia empírica lleva a pensar que los microempresarios recurren al mercado extra bancario donde el costo del crédito es más caro que el vigente en el mercado financiero bancario, a fin de satisfacer su demanda de crédito para pagar mano de obra, insumo y materias primas cuando no obtienen crédito del proveedor o el plazo que éste le concede es insuficiente.

Otros factores que los entrevistados consideraron importantes fueron: incremento en los precios (30\%), la competencia $(14 \%)$, tecnología poco adecuada (13\%) y la disponibilidad de materia prima $(12 \%)$.
Con respecto a la competencia, el $52 \%$ de los microempresarios consideran que sus competidores son otras empresas similares a las de ellos, mientras que el $48 \%$ respondió ser las pequeñas em. presas.

Es logico pensar que la desigualdad de condiciones de las microempresas en relación a las grandes y medianas empresas hace imposible que exista competencia entre ambas. De tal manera que sus competidores más cercanos son otras empresas de su misma naturaleza, de alli la importancia que cada microempresa se desarrolle y fortalezca para satisfacer las necesidades y deseos de los consumidores mejor que sus competidores. Permitiendo así, que este esfuerzo individualizado converja en un punto común, logrando que el sector microempresarial crezca y se consolide.

Por otra parte, el $42 \%$ de los microempresarios consideran que su negocio compite en precio (éstos opinan que su precio es el más bajo del mercado); a la par, el $37 \%$ opinan que sus productos o servicios son de muy buena calidad y ello es un factor altamente competitivo.

El $21 \%$ afirman que el sistema de ventas que ellos ofrecen (apartados, ofertas, descuentos por volumen de compra, descuentos por pronto pago, etc) les permite competir en el mercado.

En cuanto al abastecimiento de materia prima, los microempresarios no utilizan mecanismos apropiados para tal fin, como por ejemplo uniones de compras, cooperativas de insumos, centros de acopio, sistemas grupales de compras, entre otros. 
Figura 6

Mecanismos de abastecimiento de materia prima en microempresas de

Maracaibo

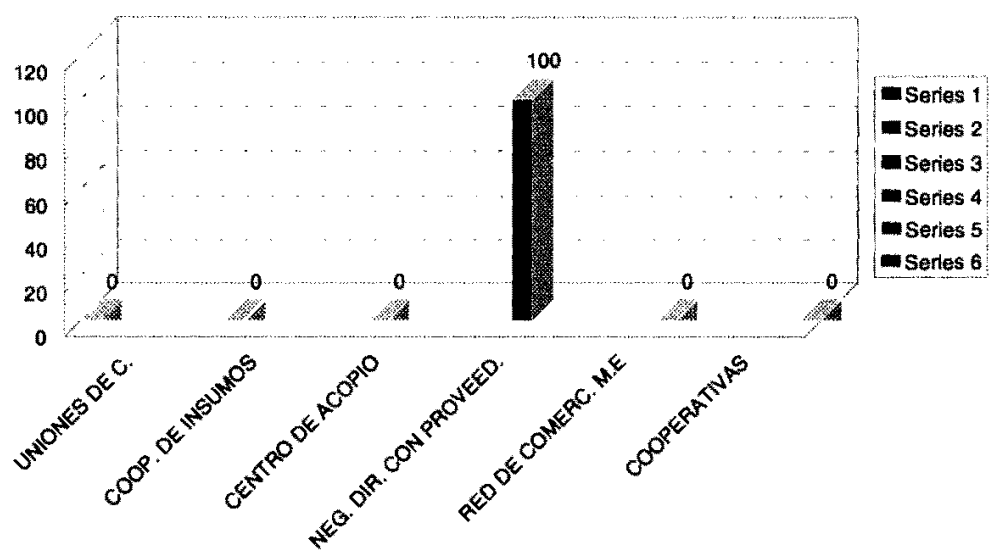

El total de microempresarios entrevistados coincidieron en afirmar, que para abastecerse de materia prima para elaborar sus productos o prestar sus servicios, negocian directamente con los proveedores de la misma; es decir acuden a estos proveedores en forma individual y aislada, teniendo, de ésta manera, poco o nulo poder de negociación frente a ellos, debido a que, generalmente, son los mismos proveedores de siempre, y compran la materia prima bajo las condiciones que éstos les impongan (Figura No. 6).

Para la mayoría $(83 \%)$, las grandes empresas constituyen los principales proveedores de materiales e insumos a las pequeñas unidades productivas. Se puede decir que estos grandes proveedores le otorgan créditos a los microempresarios, estableciéndose una relación de dependencia y subordinación de los microempresarios respecto a las grandes empresas, en donde éstas imponen sus precios y condiciones de pago traduciéndose en desventajas para el sector mi- croempresarial con respecto al sector formal de la economía.

En otro orden de ideas, el mayor porcentaje de microempresarios $(69 \%)$ no toma en consideración las características de los potenciales consumidores (zona geográfica, edad, sexo, estrato socio - económico y nivel educativo), para colocar sus productos o prestar sus servicios en el mercado. De igual manera, el $85 \%$ no consideran los niveles de ocupación y el $81 \%$ no comercializa sus productos o servicios de acuerdo a grupos poblacionales, lo cual evidencia un total desconocimiento de los criterios de segmentación del mercado, afectando considerablemente la comercialización de sus productos o servicios.

Ahora bien, al considerar el conocimiento que los microempresarios tienen del mercado, se llegó a determinar que no hacen uso de las técnicas de investigación de mercados para colocar sus productos o prestar sus servicios. Esta afirmación se sustenta al analizar los resul- 


\section{Figura 7}

Frecuencia en que se analiza el mercado en microempresas de Maracaibo

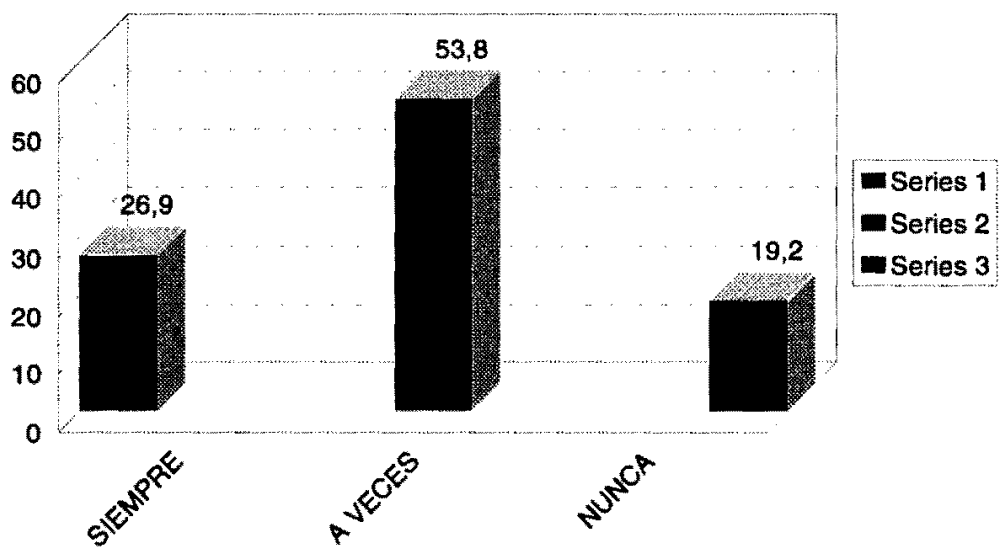

tados obtenidos en la encuesta (Figura 7). Se puede observar, que investigan el mercado empíricamente. En donde el $27 \%$ afirma que "siempre" analiza su mercado y el $54 \%$, lo hace en ciertas ocasiones, mientras el $19 \%$ respondió que nunca estudia las condiciones del mercado. Probablemente esta debilidad de los microempresarios sea el reflejo, entre otras causas, del hecho de que un porcentaje considerable de los mismos $(69 \%)$ no habian recibido hasta el momento de la encuesta formación ni asesoramiento técnico en mercadeo.

Un segmento considerable de los microempresarios entrevistados, señalaron lo importante que resulta para ellos recibir capacitación y asistencia técnica en las áreas de promoción y ventas $(60 \%)$, el resto consideró prioritario los aspectos contables y administrativos $(16 \%)$, entrenamiento de personal $(14 \%)$ y en el área tecnológica (10\%).

En relación a la asistencia que los microempresarios requieren en el área tecnológica, es preciso señalar que en la medida que éstos introduzcan tecnología adecuada para mejorar su proceso productivo y se les brinde el entrenamiento necesario a ellos y a sus operarios, en esa misma medida sus productos o servicios tendrán una mejor aceptación en el mercado, debido a que la calidad de los mismos mejorará, manifestándose por la preferencia, que de ellos tendrán los consumidores al momento de tomar la decisión de compra.

\section{Conclusiones}

De los resultados obtenidos, en el análisis realizado en el presente articulo, se desprenden las siguientes conclusiones:

Existe un total desconocimiento de los criterios de segmentación del mercado; por tal motivo, a los microempresarios se les dificulta llegar con éxito al mercado meta.

Debido a su escasez de capital y su 
informalidad, la microempresa dispone de una gran flexibilidad para aprovechar las oportunidades del mercado y para enfrentar bajas coyunturales no sólo en el mediano, sino también en el corto plazo.

Por otro lado, gracias al uso generalizado de las mismas herramientas, la venta a una clientela constituida, en mucho de los casos, en base a relaciones personales y porque apenas mantiene una provisión mínima de materia prima (mantiene bajos inventarios), los microempresarios pueden pasar de un producto o servicio a otro, cuando el primero no tiene demanda o está dejando poca ganancia o simplemente cuando el segundo constituye una novedad en el mercado.

Una de las múltiples estrategias que han desarrollado los propietarios de las unidades económicas informales estudiadas, ha sido ofrecer dos o más líneas de productos o servicios. Esto se explica, tal vez, por el hecho que para mantener un sólo producto o una sola línea de producción, comercialización y servicio, es indispensable que existan ciertas condiciones de permanencia, regularidad y situaciones ventajosas respecto al abastecimiento y a la demanda, cuestión que es muy difícil conseguir en los actuales momentos en donde existe una fuerte variación de la oferta y la demanda en el mercado.

La diversificación de las líneas de productos o servicios es a veces coyuntural; se rigen por situaciones especificas, como por ejemplo, las características de la demanda en algunas épocas del año (navidad, período vacacional, comienzo de año escolar, etc). En otros casos la oferta diversificada proviene del aprovechamiento del material residual o de desecho de la línea principal.

La carencia de habilidades y destrezas por parte del operario, asi como los vacíos en organización, técnicas de promoción y ventas (tecnología blanda) por parte del microempresario, limita mayores volúmenes de ventas e ingresos en el sector; de igual forma los problemas inherentes al proceso productivo (tecnología dura) son factores que imposibilitan obtener nuevos clientes y atender nuevos segmentos de mercado. Por tal motivo se recomienda a todos aquellos organismos, tanto públicos como privados, dedicados a brindar asistencia y apoyo a las microempresas, dirigir sus esfuerzos hacia la capacitación del empresario informal en aspectos de organización y dirección, comercialización y financiamiento para lograr el desarrollo integral de la microempresa. Además se debe habilitar y capacitar permanentemente la mano de obra, calificándola específicamente de acuerdo a los requerimientos conyunturales de cada subsector de la producción, generando de esta manera mayores niveles de calidad y productividad, haciendo el producto cada vez más accesible a diferentes y nuevos mercados.

En cuanto a las estrategias que emplean los microempresarios entrevistados para fijar los precios de venta de sus productos o servicios, se tiene que, éstos toman como criterio, en primer lugar, los precios de venta de la competen. cia y en segundo término establecen como parámetro los costos de producción.

Adicionalmente, definen ciertas po- 
liticas de descuento sobre los precios establecidos de acuerdo a los márgenes de ganancia o incentivan la compra de sus productos o servicios a través de descuentos otorgados por volúmenes y facilidades crediticias principalmente.

Para promocionar sus productos y servicios, los microempresarios hacen poco uso de los medios publicitarios, impidiéndose el posicionamiento en el mercado, es decir, lograr que los productos y servicios que ellos ofrecen ocupen un lugar claro, distinto y superior en la mente de los consumidores meta en comparación con la competencia.

Los microempresarios deben planificar las estrategias de publicidad y promoción del producto, de manera tal que les permita darlo a conocer en el mercado local y nacional en forma masiva. Para ello deben ejecutar actividades promocionales como las ventas personales a los distribuidores, utilizar la formula de presentación de sus productos como un elemento promocional para atraer la atención de los consumidores y realizar promociones de venta como exposiciones, demostraciones, obsequio, muestras, entre otras.

Un porcentaje considerable de microempresarios (46\%) utilizan como estrategia la venta a particulares, en donde adquieren la modalidad de trabajos a pedido de clientes individuales exigiendo un adelanto que por lo general gira alrededor del cincuenta por ciento del valor total de la obra, cantidad que le garantiza la compra de insumos y materia prima. Esta manera de funcionar genera una forma de abastecimiento al menudeo que inevitablemente hace poco competitivo el pro- ducto o servicio frente a las empresas del sector informal .

Los obstáculos y problemas que entrentan los microempresarios, se inician al momento mismo en que se vinculan al mercado, tanto para abastecerse de insumos y materias primas que requiere el proceso productivo, como al vender los resultados de su trabajo.

Los microempresarios se encuentran vulnerables a los vaivenes del mercado, donde intervienen una serie de factores exógenos en los cuales ellos no tienen ninguna capacidad de ingerencia $y$ control.

Es importante que los microempresarios se organicen por ramas homogéneas de la producción a fin de unir esfuerzos para comprar, vender y resolver grupalmente problemas inherentes a la producción y distribución de productos y servicios.

Los microempresarios se deben organizar en uniones de compra, cooperativas de insumos, centros de acopio, negociaciones gremiales con proveedores sobre cupos y descuentos o sistemas de compras grupales a fin de contrarrestar las dificultades que se le presentan a aquellos que actúan en forma individual y aislada para adquirir materia prima $e$ insumos.

En líneas generales se puede concluir que:

- El mercadeo es débil en las microempresas analizadas. Los propietarios de las Unidades Económicas estudiadas están mas orientados hacia la producción bajo el supuesto de que "lo que se produce se vende". Además los microempresarios, en casos excepcionales, 
investigan su mercado y planean su acción de mercadeo. Se limitan a ejecutar personalmente la actividad de ventas sin una estrategia definida.

- Los microempresarios entrevistados no están en condiciones de contratar expertos que investiguen el mercado, debido a los altos costos que este estudio representa para ellos. Sin embargo, necesitan obtener buena información de mercadotecnia para así conocer las señales del mercado y poder comercializar con éxito sus productos o servicios.

Se sugiere que para investigar el mercado, los microempresarios se pueden valer de ciertas técnicas en donde los costos pueden ser reducidos y además obtener información confiable para mejorar la toma de decisión de mercadotecnia.

En este sentido, es recomendable utilizar la técnica de la "observación". Para ello, pueden visitar los establecimientos de sus competidores para comparar los productos y los precios. También pueden evaluar su mezcla de clientes verificando cuántos y de qué tipo son en diferentes momentos del día. Pueden hacer entrevistas informales, en donde se planteen algunos objetivos y formulen una serie de preguntas capaces de dar respuesta a sus necesidades de información.

\section{Referencias Bibliográficas}

AAKER, David y DAY George. (1996). "Investigación de Mercados ". México. Editorial Interamericana. Pág 375.

ARBOLEDA, José . (1992). " La Experiencia Colombiana de Apoyo a la Microempresa". Impacto de las Politicas Estadales de Apoyo a la Econo- mía Popular (Ponencia). Caracas. pp.12.

CARTAYA, Vanessa y BETANCOURT, Keida. (1991). "La Microempresa en la Dinámica Económica y Social". Un Estudio del Area Metropolitana de $\mathrm{Ca}$ racas. Instituto de Investigaciones de Ciencias Sociales (CISOR). Caracas. pp. 7.

CHAVEZ O BRIEN, Eliana. "Microempresas y Desarrollo Económico". (1987). Revista Nueva Sociedad. No. 90 . Julio - Agosto. pp 155.

FERNANDEZ, Mariela. (1991). "Concepción y Filosofía del Programa de Apoyo a la Economia Popular y Ejecución en el Estado Zulia". Primera Jornada Regional de Economía Popular (Ponencia). Maracaibo. pp. 7.

FREITES, Nelson. (1988). "EI Sector Informal en Venezuela". Evaluación Reciente. Magnitudes e Implicaciones Sociopolíticas. I Congreso Venezolano de Relaciones de Trabajo. FUNDECO. Barquisimeto. pp 17.

FREITES, Nelson; AVILA, María T. (1990). " Concertación, Flexibilidad y Transparencia". Características fundamentales del Programa de Apoyo a las Microempresas y Artesanos del estado Lara (PAMEL). Seminario Internacional de Economía Popular. Fundación para el Desarrollo de la Región Centro - Occidental de Venezuela (FUNDECO). (Ponencia). Caracas .

GIMENEZ G. y Colaboradores. (1990). Estrategies Organizativas de Comercialización de Insumos y Bienes Producidos por las Microempresas. (Ponencia). (CEPROPMI). pp. 6.

IRANZO, Mauricio SASSONE, Pedro; VARGAS, Mireya. (1989). "Líneas Estratégicas del Programa de Promoción y Apoyo a la Economía Popular (Caso Venezuela) ". Seminarios 
Internacional de Economía Popular.(Ponencia).Caracas. pp.26.

MENDOZA DE PULIDO, Luisa. (1988). “El Empresario Venezolano frente al paso del futuro ". Citado por Lovera y Espinoza." Apoyo a la Microempresa en Venezuels". (Ponencia). Seminario. El Sector Informal Urbano. Barquisimeto. pp 6.

PANGOURELIS. "Las Gobernaciones de Estado y los Programas de Apoyo a la Microempresa". (1988). Fundación para el Desarrollo de las Microempresas del Estado Lara (FUNDEME). (Ponencia). Barquisimeto. pp. 12.

PARAA ESCOBAR, Ernesto. (1994) . "La Capacitación al Servicio de la comercialización y Organización Microempresarial. (Ponencia). FUNDECO. Barquisimeto.

PORTES, A y SHAUPPIER, R. (1993). "De la Mano de Obra Excedente a la Empresa Dinámica". Perspectivas de Competencia del Sector Empresarial Latinoamericano. Estudios Sociológic08. Vol. XI. No. 33. Septiembre Diciembre. México. pp. 847.

PRESIDENCIA DE LA REPÚBLICA. OFICINA CENTRAL DE ESTADISTICA E INFORMÁTICA. (1988) . "Fuerza de Trabajo ". Consideraciones Básicas. Caracas. Capitulo III.
PRESIDENCIA DE LA REPÚBLICA. OFICINA CENTRAL DE ESTADISTICA E INFORMÁTICA (1984 - 1993). "Indicadores de la Fuerza de Trabajo". Caracas. Segundo Semestre.

QUINTERO URIBE, Victor M. " Programa de Mercadeo con y para la Microempresa". La Experiencia Colombiana (Borrador Preliminar).

RAMIREZ VILLACOSTA, Yolanda. (1992). " Microempresa y Comerclallzación en el Perú". Seminario Internacional de Microempresas, Organización, Innovación Tecnológica y Comercialización.(Ponencia).Caracas. pp. 19.

SANCHEZ UGARTE, Fernando. (1993) . "Acciones en favor de las Micro,Pequeña y Mediana Industria en México". Revista Comercio Exterior. Vol. 43. No. 6. Junio.

SEMINARIO INTERNACIONAL DE MICROEMPRESAS. " Organización, Innovación, Tecnológica y Comercialización". (Ponencia). Caracas. Noviembre 1992. pág 23.

STANTON, William y FUTRELL, Charles. (1970). "Fundamentos de la Mercadotecnia". México. Octava Edición. Mc. Gran Hill. Pág 570.

TAYLOR/KINNEAR. (1990). "Investigación de Mercados ". Un Enfoque Aplicado. Bogotá. Tercera Edición. Pág 630. 